\title{
Predictors of provider- initiated HIV testing and counseling refusal by outpatient department clients in Wolaita zone, Southern Ethiopia: a case control study
}

Wolde Facha ${ }^{1 *}$, Wondewosen Kassahun ${ }^{2}$ and Abdulhalik Workicho ${ }^{2}$

\begin{abstract}
Background: Despite different strategies designed to rapidly identify HIV infected individuals, majority of HIVinfected people are unaware of their sero-status in developing countries. The objective of this study was to assess predictors of provider-initiated HIV testing and counseling (PITC) refusal by outpatient department (OPD) clients in Wolaita zone, Southern Ethiopia.

Methods: Facility based unmatched case control study was conducted on outpatient department clients in randomly selected seven health facilities in Wolaita zone, Southern Ethiopia in February 2012. A total of 291 participants (97 cases and 194 controls) were included in our study. Cases were patients who refused HIV test while controls were patients who tested for HIV after provider-initiated HIV testing and counseling (PITC) recommendation by outpatient department (OPD) clinicians. We used both quantitative and qualitative methods of data collection. Pretested interviewer administered questionnaires were used to collect quantitative data by trained nurses, and in-depth interview with 14 OPD clinicians was conducted by principal investigator to supplement quantitative findings. Bivariate and multivariate analyses were done to identify independent predictors of providerinitiated HIV testing and counseling refusal by OPD clients.
\end{abstract}

Result: Study participants who had stigmatizing attitude $[A O R=6.09,(95 \% \mathrm{Cl}: 1.70,21.76)]$, who had perceived risk for HIV infection [AOR $=5.23$, (95 \% Cl: 2.22, 12.32)], who did not perceive the benefits of provider-initiated HIV testing and counseling $[\mathrm{AOR}=4.64,(95 \% \mathrm{Cl}: 1.79,12.01)]$, who did not get minimum recommended pretest information from their providers [AOR $=2.98,(95 \% \mathrm{Cl}$ : 1.06, 8.35)], who ever not heard of provider-initiated HIV testing and counseling service $[A O R=2.41,(95 \% \mathrm{Cl}: 1.14,5.09)]$, and who were from urban area $[A O R=2.40,(95 \%$ $\mathrm{Cl}=1.26,4.57)]$ were more likely to refuse provider-initiated HIV testing and counseling service than their counterparts.

Conclusion: Knowledge on HIV/AIDS, attitude towards people living with HIV/AIDS and perceived risk for HIV infection by clients were the major barriers for provider-initiated HIV testing and counseling acceptance. Health professionals working at outpatient department should give due attention to overcome these barriers so as to enhance HIV testing acceptance by their clients.

Keywords: Provider-initiated HIV testing and counseling, PITC, HIV testing, Wolaita zone, Southern Ethiopia

\footnotetext{
* Correspondence: woldiefacha@gmail.com

${ }^{1}$ School of Public Health, College of Health Sciences and Medicine, Wolaita

Sodo University, Wolaita SodoP.O.Box 138Ethiopia

Full list of author information is available at the end of the article
} 


\section{Background}

About 34 million people ( $0.5 \%$ of the world population) were living with HIV/AIDS in 2010 (estimates range from 30.9 to 36.9 million) [1]. Sub-Saharan Africa remains the most heavily affected region, accounting for $71 \%$ of all new HIV infections in 2008 [2]. However, only $10 \%$ of men and $12 \%$ of women had been tested for HIV, implying that the majority of HIV- infected persons in this region are unaware of their sero status [2, 3]. With an estimated 1.1 million people living with HIV, Ethiopia is one of the 22 most affected countries in the world [4, 5]. The Government of Ethiopia set national HIV/AIDS policy in 1998 to create an enabling environment to fight the pandemic [6-8]. However, most HIVinfected patients globally, and particularly in resourcepoor settings, are currently unaware of their HIV status due to various reasons [9]. Among all types of HIV testing, provider-initiated HIV testing and counseling (PITC) has been identified as a priority intervention to increase access to treatment, care and support for HIV infected individuals [9-11]. Provider-initiated HIV testing and counseling is HIV testing and counseling service recommended by health care provider to clients attending health facility as a standard component of medical care. Previously it was given at outpatient department (OPD) for patients with possible sign of HIV infection but now, as per WHO recommendation, the service is given to all clients as standard components of medical care not to miss HIV positive individuals seeking medical care [12-15]. After the introduction of the service, PITC refusal among adult patients at OPD was 5-25\% in different African countries [16, 17]. However, study conducted in our country even with possible sign of HIV infection showed that its refusal was about $32 \%$ [18]. Thus, the government of Ethiopia has been using different strategies to encourage people to be tested for HIV. These includes escalating static and mobile voluntary counseling and testing (VCT) site, strengthening prevention of mother-to-child transmission (PMTCT) service, conducting campaign for HIV testing, enrolling HIV positive individuals to care and treatment program free of charge, etc. [10]. Despite these efforts to enhance HIV teting many people are still unaware of their serostatus which might be contributed by several factors. However, most of the researches conducted on PITC utilization addressed patients' related factors. However, patients' related factors were not the only factors affecting PITC refusal. Therefore, this study assessed both patients' and providers' related factors affecting PITC refusal at selected health facilities in Wolaita zone, Southern Ethiopia.

\section{Methods}

\section{Study design and setting}

We conducted facility based unmatched case-control study in February, 2012 in Wolaita zone, Southern
Ethiopia. Wolaita zone is administratively divided in to twelve districts and three town administrations. Based on the 2007 census conducted by the Central Statistical Agency of Ethiopia (CSA), the population of Wolaita zone was projected to be $1,901,112$ for the year $2012 / 13$ (making it one of the most densely populated areas in the country). Among them, $96.31 \%$ were Wolaita ethnic groups, $49.2 \%$ were men and $11.49 \%$ were urban inhabitants. (Urban was defined as localities of 2,000 or more inhabitants) [19]. Wolaita zone is located at a distance of $328 \mathrm{~km}$ south of the capital city (Addis Ababa). The zonal town (Soddo) is pathway for many travellers and tourists since it has five transportation gates to the nearby zonal towns. The major economic activities are agriculture (production of legumes, root crops and some cereals - predominantly maize), and livestock rearing which is source of income for about $88.5 \%$ of population [20]. The zone has three hospitals, 71 health centers, 372 health posts and 98 private clinics. All hospitals and health centers were providing PITC service for OPD patients; however only three hospitals and thirteen health centers were providing antiretroviral therapy (ART) during the study period. We randomly selected two hospitals and five health centers among those facilities having HIV care and treatment programs.

\section{Study participants}

Study population for cases were adult patients (age 1564 years) who refused HIV test while for controls were adult patients who were tested for HIV after providerinitiated HIV testing and counseling recommendation by OPD clinicians. Cases were adult patients who refused HIV test while controls were adult patients who were tested for HIV after provider-initiated HIV testing and counseling recommendation by OPD clinicians.

\section{Sample size and sampling technique}

We used both quantitative and qualitative methods of data collection. Sample size for quantitative study was calculated using OpenEpi (Epidemiologic Statistics for Public Health, version 2.2) by using proportion of cases and controls with high perceived stigma towards people living with HIV/AIDS (PLWHAs) of 69.15 and $38.29 \%$ respectively [21], confidence interval $(\mathrm{CI})$ of $95 \%$, power of $90 \%$, case to control ratio of 1:2 [18], design effect of 2 and $10 \%$ possible non-response rate. Thus, the total of 291 OPD clients (97 cases and 194 controls) were participated in quantitative study and 14 OPD clinicians (two from each facility) were purposely included for indepth interview. Study subjects were allocated proportionally to the respective health facilities based on patients flow and selected consecutively until the expected sample size was obtained. 
Table 1 Socio-demographic characteristics of patients attending OPD of selected health facilities in Wolaita zone, Southern Ethiopia, February 2012

\begin{tabular}{|c|c|c|c|}
\hline Variable & $\begin{array}{l}\text { Case }(n=97) \\
\#(\%)\end{array}$ & $\begin{array}{l}\text { Control }(n=194) \\
\#(\%)\end{array}$ & $P$-value \\
\hline Age & & & 0.509 \\
\hline $15-24$ & $41(42.3)$ & $70(36.1)$ & \\
\hline $25-34$ & $30(30.9)$ & $72(37.1)$ & \\
\hline $35-64$ & $26(26.8)$ & $52(26.8)$ & \\
\hline Sex & & & 0.678 \\
\hline Male & $45(46.4)$ & $95(49)$ & \\
\hline Female & $52(53.6)$ & $99(51)$ & \\
\hline Residence & & & 0.136 \\
\hline Rural & $45(46.4)$ & $108(55.7)$ & \\
\hline Urban & $52(53.6)$ & $86(44.3)$ & \\
\hline Marital status & & & 0.031 \\
\hline Married & $50(51.5)$ & $130(67)$ & \\
\hline Single & $39(40.2)$ & $56(28.9)$ & \\
\hline Divorced/Widowed & $8(8.2)$ & $8(4.1)$ & \\
\hline Formal education & & & 0.132 \\
\hline No & $22(22.7)$ & $30(15.5)$ & \\
\hline Yes & $75(77.3)$ & $164(84.5)$ & \\
\hline Occupation & & & 0.53 \\
\hline Employed & $21(21.6)$ & 36 (18.6) & \\
\hline Unemployed & $76(78.4)$ & $158(81.4)$ & \\
\hline Av. household income & & & 0.184 \\
\hline$<500$ & $25(25.8)$ & $30(15.5)$ & \\
\hline $501-1000$ & $36(37.1)$ & 77 (39.7) & \\
\hline $1001-1500$ & $25(25.8)$ & $56(28.9)$ & \\
\hline$>1501$ & $11(11.3)$ & $31(16.0)$ & \\
\hline
\end{tabular}

\section{Data collection and measurement}

We used Amharic and Wolaytigna (local language) version questionnaire to collect data from patients who had willingness to be included in the study at private room arranged for this purpose. Seven diploma nurses for data collection and four supervisors who have first degree in public health were used after 2 days training. Questionnaire was pre-tested on $10 \%$ of clients at Sodo Christian Hospital which was not included in the study, and discussion was held based on the result of the pre-test and necessary correction was done. The questionnaire addressed socio demographic characteristics, knowledge on HIV, KAP on PITC, perceived benefits for HIV test, perceived risk to HIV infection and HIV related stigma to assess patients' related factors; and whether the providers have given minimum recommended pretest information, post-test counseling, linked HIV positive patients to care, treatment and support or not were used to assess providers' related factors. For qualitative study, in-depth interview with OPD clinicians were conducted to assess patients' and providers' related factors. It focused mainly on how PITC was implemented at their health facility, major facilitators and barriers to PITC service by patients, type of services delivered to HIV positive patients and problems faced while implementing PITC service at their health facility. Note taking and digital record was conducted during in-depth interview not to miss important points. Knowledge on HIV status was assessed by five questions related to HIV prevention and common misconceptions and those who answered all questions correctly were categorized as knowledgeable otherwise not knowledgeable. Stigma towards people living with HIV/AIDS was assessed using five questions. Those who were no stigmatizing idea for all five questions were categorized as no stigma while those individuals who have stigmatizing idea for at least one of five questions related to stigma were categorized as having stigma towards people living with HIV/AIDS. Those respondents who believed that PITC is beneficial for themselves were categorized as having perceived benefit for HIV testing while those respondents with feeling of vulnerability of being infected by HIV were operationalized as having perceived risk for HIV infection. Minimum recommended pretest informations on PITC are the informations on HIV transmission and prevention methods, patients' right to decline HIV test, benefits and confidentiality of HIV test given to patients by OPD clinicians.

\section{Data analysis}

Data was checked for completeness, edited, coded and entered into Epi data version 3.1 and exported to SPSS 16.0 statistical software for analysis. Double entry was done by principal investigator before analysis. Descriptive analysis was made to explain summary values and characteristics of participants. Bivariate analysis was done and all explanatory variables which have association with the outcome variable with $p$ value less than 0.2 were included in multivariate analysis. Then multivariate analysis using stepwise selection method (backward LR) was employed to determine independent predictors among explanatory variables for PITC refusal. OR with $95 \%$ CI were used to decide whether those independent variables included in multivariate analysis were statistically significant or not with outcome variable (PITC refusal). Finally qualitative findings were categorized on key thematic areas to supplement quantitative findings.

\section{Results}

A total of 291 OPD clients (97 cases and 194 controls) were selected for our study and the response rate was $100 \%$. 
Table 2 Knowledge on HIV prevention and common misconceptions by cases and controls who attended OPD of selected health facilities in Wolaita zone, Southern Ethiopia, February 2012

\begin{tabular}{|c|c|c|c|}
\hline Variables & $\begin{array}{l}\text { Case }(n=97) \\
\#(\%)\end{array}$ & $\begin{array}{l}\text { Control }(n=194) \\
\#(\%)\end{array}$ & $\begin{array}{l}\text { Crude OR } \\
(95 \% \text { Cl) }\end{array}$ \\
\hline \multicolumn{4}{|c|}{ Faithfulness to partner reduce the risk of HIV transmission } \\
\hline Yes & $58(59.8)$ & $148(76.3)$ & 1 \\
\hline No & $39(40.2)$ & $46(23.7)$ & $2.16(1.28,3.65)^{\mathrm{a}}$ \\
\hline \multicolumn{4}{|c|}{ Consistent use of condom reduce the risk of HIV transmission } \\
\hline Yes & $50(51.5)$ & $125(64.4)$ & 1 \\
\hline No & $47(48.5)$ & $69(35.6)$ & $1.7(1.04,2.79)^{a}$ \\
\hline \multicolumn{4}{|c|}{ Healthy-looking person can have HIV } \\
\hline Yes & $61(62.9)$ & $161(83.0)$ & 1 \\
\hline No & $36(37.1)$ & $33(17.0)$ & $2.88(1.65,5.02)^{\mathrm{a}}$ \\
\hline \multicolumn{4}{|c|}{ Person can get HIV from mosquito bites } \\
\hline Yes & $32(33)$ & $48(24.7)$ & $1.5(0.88,2.56)$ \\
\hline No & $65(67)$ & $146(75.3)$ & 1 \\
\hline \multicolumn{4}{|c|}{ Person can get HIV by sharing meal with infected patients } \\
\hline Yes & $12(12.4)$ & $17(8.8)$ & $1.47(0.67,3.22)$ \\
\hline No & $85(87.6)$ & $177(91.2)$ & 1 \\
\hline \multicolumn{4}{|l|}{ Knowledge status on HIV } \\
\hline Not knowledgeable & $72(74.2)$ & $121(62.4)$ & $1.74(1.02,2.98)^{\mathrm{a}}$ \\
\hline Knowledgeable $^{\mathrm{b}}$ & $25(25.8)$ & $73(37.6)$ & 1 \\
\hline
\end{tabular}

${ }^{a}$ Variable showing significant association during bivariate analysis

${ }^{b}$ Knowledgeable on HIV/AIDS - individuals who correctly responded for all of the questions related to HIV prevention and common misconceptions

\section{Socio-demographic characteristics}

About $73 \%$ of cases as well as controls were in the age group between 15 to 34 years, and the median age for cases was 25 years and that for controls was 27 years. About $53.6 \%$ of cases and $51 \%$ of controls were female in which $46.4 \%$ of cases and $55.7 \%$ of controls live in rural areas. Majority of study participants were married (51.5\% for cases and $67 \%$ for controls), attended formal education (77.3\% for cases and $84.5 \%$ for controls) and unemployed (78.4\% for cases and $81.4 \%$ for controls) (Table 1).

Knowledge on HIV prevention and common misconceptions About $40.2 \%$ of cases and $23.7 \%$ of controls did not believe that the risk of HIV transmission is reduced by having sex with only one faithful uninfected partner. Regarding their knowledge on HIV prevention and major misconceptions, $74.2 \%$ of cases and $62.4 \%$ of controls were not knowledgeable (Table 2).

\section{Knowledge and attitude towards PITC}

Among the study participants, $44.3 \%$ of cases and $12.4 \%$ of controls were ever not heard of PITC. However, majority of the study participants knew that patients have the right to decline HIV test $(95.9 \%$ for cases and $96.9 \%$ for controls), supported provision of
PITC service to all OPD patients (58.8\% for cases and $93.8 \%$ for controls) and perceived the benefits of PITC (59.8\% for cases and $95.4 \%$ for controls) (Table 3 ).

\section{Practice of HIV test}

Among the study participants, 55(56.7\%) of cases and $132(68 \%)$ of controls had ever been tested for HIV prior to our study. From those who ever been tested before, $40 \%$ of cases $(n=55)$ and $51.5 \%$ of controls $(n=132)$ were tested by PITC approach.

\section{Perceived risk to HIV infection}

Thirty-four percent of cases and $6.2 \%$ of controls perceived themselve being at risk for HIV infection. Qualitative findings also revealed that those patients who perceived themselve being at higher risk to acquire HIV infection due to multiple sexual partner and/or unprotected sexual practice refused HIV test than individuals with no risk perception.

\section{Perceived benefits of HIV testing}

About $59.8 \%$ of cases and $95.4 \%$ of controls perceived the benefits of provider-initiated HIV testing and counseling. During qualitative study, a 28 years old male OPD clinician from Otona hospital said that those who have information on available services in our hospital 
Table 3 Knowledge and attitude towards PITC service by cases and controls who attended OPD of selected health facilities in Wolaita zone, Southern Ethiopia, February 2012

\begin{tabular}{|c|c|c|c|}
\hline Variables & $\begin{array}{l}\text { Case }(n=97) \\
\#(\%)\end{array}$ & $\begin{array}{l}\text { Control }(n=194) \\
\#(\%)\end{array}$ & $\begin{array}{l}\text { Crude OR } \\
(95 \% \mathrm{Cl})\end{array}$ \\
\hline \multicolumn{4}{|c|}{ Ever heard of PITC } \\
\hline Yes & $54(55.7)$ & $170(87.6)$ & 1 \\
\hline No & $43(44.3)$ & $24(12.4)$ & $5.64(3.14,10.13)^{a}$ \\
\hline \multicolumn{4}{|c|}{ Know PITC is given to all OPD patients } \\
\hline Yes & $57(58.8)$ & $146(75.3)$ & 1 \\
\hline No & $40(41.2)$ & $48(24.7)$ & $2.14(1.27,3.59)^{a}$ \\
\hline \multicolumn{4}{|c|}{ Patient has right to refuse PITC } \\
\hline Yes & $93(95.9)$ & $188(96.9)$ & 1 \\
\hline No & $4(4.1)$ & $6(3.1)$ & $1.35(0.37,4.89)$ \\
\hline \multicolumn{4}{|c|}{ Patients are benefited from PITC service } \\
\hline Yes & $89(91.8)$ & $187(96.4)$ & 1 \\
\hline No & $8(8.2)$ & $7(3.6)$ & $2.4(0.84,6.83)$ \\
\hline \multicolumn{4}{|c|}{ Support provision of PITC service to all OPD patients } \\
\hline Yes & $57(58.8)$ & $182(93.8)$ & 1 \\
\hline No & $40(41.2)$ & $12(6.2)$ & $10.64(5.23,21.66)^{a}$ \\
\hline \multicolumn{4}{|c|}{ Perceive the benefits of PITC } \\
\hline Yes & $58(59.8)$ & $185(95.4)$ & 1 \\
\hline No & $39(40.2)$ & $9(4.6)$ & $13.82(6.32,30.23)^{a}$ \\
\hline \multicolumn{4}{|c|}{ PITC can affect health service utilization by patients } \\
\hline No & $81(83.5)$ & $181(93.3)$ & 1 \\
\hline Yes & $16(16.5)$ & $13(6.7)$ & $2.75(1.26,5.98)^{a}$ \\
\hline
\end{tabular}

${ }^{a}$ Variable showing significant association during bivariate analysis

(curative, preventive and supportive services), if they were found to be positive, did not refuse providers' recommendation as compared to those who have no information on it.

\section{Stigma towards PLWHAs}

Our study showed that about $96.9 \%$ of cases and $78.9 \%$ of controls had stigmatizing idea towards PLWHAs. Qualitative study also strengthened that stigma remains the most important barrier among patients to accept providers' recommendation for HIV test.

\section{Pretest information}

Concerning pretest information, study participants who did not get minimum recommended pretest information as per the PITC guidelines from their providers were $91.8 \%$ for cases and $78.4 \%$ for controls. The main reasons, as mentioned in qualitative study, were patient load and staff shortage. ".....I did not face any patients who refused HIV test when pretest information were properly given but due to patient load and staff shortage, sometimes, we were obliged to skip some of pretest information; even some of the patients were not recommended at all, which might result in PITC refusal". (32 years old, Male Physician, Ottona Hospital).

\section{Multivariate analysis}

In multivariate analysis, HIV related stigma, perceived risk for HIV infection, perceived benefits of PITC, pretest information related to PITC, ever heard of PITC service and residence have shown statistically significant association with outcome variable in the study area (Table 4).

\section{Discussion}

Provider-initiated HIV testing and counseling (PITC) is important strategy designed to scale up HIV detection and play significant role to prevent and control its transmission. Though its implementation started since 2005, significant number of individuals still did not accept PITC recommendation in our country [22-24]. Thus, this study attempted to assess determinants of PITC refusal by OPD patients.

Despite many interventions aimed to reduce HIV related stigma, still there is deep-rooted stigmatizing attitude towards PLWHAs by community which is a great challenge to prevent and control HIV transmission. Our study showed that study participants who had stigmatizing attitude towards PLWHAs were more likely to refuse PITC than individuals who had no stigmatizing attitude towards PLWHAs [AOR = 6.09, (95 \% CI: 1.70, 21.76)]. This finding was consistent with many other studies conducted in our country [21,25] and Botswana [26] in which HIV related stigma was associated with decreased odds of having been tested for HIV. Having large proportion of people with stigmatizing idea is a great challenge to attain "zero new HIV infection" slogans since it reduces an individual's willingness to be tested for HIV, to disclose their HIV status, and to access them for health care.

Individuals who had perceived risk to acquire HIV infection were more likely to refuse PITC than those who had no perceived risk for HIV infection [AOR $=5.23,(95 \% \mathrm{CI}$ : $2.22,12.32)]$. This finding was inconsistent with different studies conducted in our country on ANC attendee and TB patients such that those patients with less/no perceived risk to acquire the virus were more likely to refuse PITC than those with high perceived risk [27-29] while others showed that there was no association between risk perception and HIV test [18, 30, 31]. However, the finding was in line with the study conducted in East Gojam on TB patients such that patients with high perceived risk were more likely to refuse PITC than those with low/no perceived risk to acquire HIV infection [21]. This might be due to fear of stigma or wrong perception about the disease. It could be a great challange to control HIV transmission if those who thought them at higher risk to acquire the disease refused HIV test. 
Table 4 Independent predictors of PITC refusal by cases and controls who attended OPD of selected health facilities in Wolaita zone, Southern Ethiopia, February 2012

\begin{tabular}{|c|c|c|c|c|}
\hline Variables & Case $(n=97) \#(\%)$ & Control $(n=194) \#(\%)$ & Crude OR (95\% Cl) & Adjusted OR (95\% Cl) \\
\hline \multicolumn{5}{|c|}{ Stigma towards PLWHAs } \\
\hline No & $41(42.3 \%)$ & $165(85.1 \%)$ & 1 & 1 \\
\hline Yes & $56(57.7 \%)$ & $29(14.9 \%)$ & $8.40(2.53,27.88)^{a}$ & $6.09(1.70,21.76)^{a}$ \\
\hline \multicolumn{5}{|c|}{ Perceived risk for HIV } \\
\hline No & $64(66)$ & $182(93.8)$ & 1 & 1 \\
\hline Yes & $33(34)$ & $12(6.2)$ & $7.82(3.81,16.06)^{a}$ & $5.23(2.22,12.32)^{a}$ \\
\hline \multicolumn{5}{|c|}{ Perceived benefits of PITC } \\
\hline Yes & $58(59.8)$ & $185(95.4)$ & 1 & 1 \\
\hline No & $39(40.2)$ & $9(4.6)$ & $13.82(6.32,30.23)^{a}$ & $4.64(1.79,12.01)^{a}$ \\
\hline \multicolumn{5}{|c|}{ Got minimum recommended pretest information } \\
\hline Yes & $8(8.2)$ & $37(19.1)$ & 1 & 1 \\
\hline No & $89(91.8)$ & $157(80.9)$ & $3.07(1.38,6.84)^{a}$ & $2.98(1.06,8.35)^{a}$ \\
\hline \multicolumn{5}{|c|}{ Ever heard of PITC } \\
\hline Yes & $54(55.7)$ & $170(87.6)$ & 1 & 1 \\
\hline No & $43(44.3)$ & $24(12.4)$ & $5.64(3.14,10.13)^{a}$ & $2.41(1.14,5.09)^{a}$ \\
\hline \multicolumn{5}{|l|}{ Residence } \\
\hline Rural & $45(46.4)$ & $108(55.7)$ & 1 & 1 \\
\hline Urban & $52(53.6)$ & $86(44.3)$ & $1.45(0.89,2.37)$ & $2.40(1.26,4.57)^{a}$ \\
\hline
\end{tabular}

${ }^{\text {a }}$ Statistically significant at $P$ value less than 0.05

Study participants who did not perceive the benefits of HIV test for them were more likely to refuse PITC than their counterparts $[\mathrm{AOR}=4.64,(95 \% \mathrm{CI}=1.79,12.01)$ ]. This finding was in line with case control study conducted on TB patients and antenatal clinic attendees at Dil Chora Hospital [21, 31]. However, it was inconsistent with the descriptive cross sectional study conducted in Addis Ababa at STI clinic [32] and comparative cross sectional study conducted in Adama at TB patients [33]. The difference might be due difference in study participants and study design.

Clients who were not given minimum recommended pretest information as per the national PITC guidelines by their providers were more likely to refuse PITC than those who were given it $[\mathrm{AOR}=2.98,(95 \% \mathrm{CI}: 1.06$, 8.35)]. This might be due to the fact that those who did not get adequate pretest information could not understood the benefits of HIV test and thus refused PITC. As per the national PITC guidelines providers should give minimum recommended pretest information to all OPD clients seeking medical care; however they did not practice it consistently especially during high patient load. Thus offering HIV testing service to all individuals seeking health care had better been given due attention since it is key strategy to increase HIV test rate, early detection of the disease and enrollment of patients to care, treatment and support.
Those who ever not heard of PITC before contact with OPD clinicians were more likely to refuse PITC $[\mathrm{AOR}=2.41,(95 \% \mathrm{CI}: 1.14,5.09)]$. This finding was in line with case control study conducted in East Gojam on TB patients [21]. This could be due to the fact that those who ever not heard of PITC need more time to think of HIV test and/or discuss with whom they want before accepting PITC service. A 26 years old OPD clinician from Gununo health center said that "...those who ever not heard of PITC service did not usually show readiness for HIV test and they request extra time to discuss it with whom they want to discuss than those who ever heard of PITC". Thus, prior awareness creation on issues related to HIV testing should be considered before recommending PITC to clients at outpatient department in the study area.

Study participants who reside in urban areas were about twice more likely to refuse PITC than that of rural residence $[\mathrm{AOR}=2.40,(95 \% \mathrm{CI}=1.26,4.57)]$. This finding was inconsistent with population based study conducted in Botswana [26, 34] and facility based study conducted in our country $[25,27,30]$. This might be due to high patient flow and subsequently work load by providers in urban health facility than rural area so that urban patients did not get the minimum recommended pretest information as per the PITC guidelines to understand the benefits of HIV test. 


\section{Strength and limitation of the study}

This study addressed factors related to health care providers in addition to patients' related factors, which will help to broaden our target intervention. However, social desirability bias related to the sensitivity of topic could affect the response of the participants.

\section{Conclusion}

PITC service was not delivered to all OPD clients all the time in the study area especially at hospitals as per the national PITC guidelines. Lack of knowledge on HIV/ AIDS, stigmatizing attitude towards people living with HIV/AIDS, low perceived benefits on provider-initiated HIV testing and counseling, perceived risk for HIV infection and residing in urban areas were major barriers for provider-initiated HIV testing and counseling acceptance in our study. Therefore, concerned bodies should strengthen IEC/BCC on importance and benefits of HIV testing, especially to urban dwellers and should design and implement different strategies to washout deeprooted stigmatizing attitude towards PLWHAs to reduce PITC refusal by OPD patients.

\section{Acknowledgements}

The authors would like to thank Jimma University for financial and material support, data collectors and supervisors, patients who participated in our study, OPD clinicians for facilitating data collection process and giving valuable information.

\section{Funding}

This research work was funded by Jimma University College of Health Sciences and Medicine.

\section{Availability of data and materials}

Since the topic is sensitive, the raw data would not be deposited in publicly available repositories for confidentiality reason.

\section{Authors' contributions}

WF: Involved during study conception and design; data collection, analysis, writing the manuscript. WK: Participated in study conception and design; data analysis and interpretation of results. AW: Participated during study conception and design and write up of the manuscript. All authors read and approved the submitted version of the manuscript.

\section{Authors' information}

Wolde Facha (BSc, MPH): School of Public Health, College of Health Sciences and Medicine, Wolaita Sodo University, Wolaita Sodo, Ethiopia. P.O. Box 138. Email:woldiefacha@gmail.com.

Wondwosen Kassahun (BSc, MPH, PhD): Department of Epidemiology, College of Health Sciences and Medicine, Jimma University, Jimma, Ethiopia. P.O. Box 378. Email: wondkyt@yahoo.com.

Abdulhalik Workicho (BSC, MPH, Assistant Proffessor): Department of Epidemiology, College of Health Sciences and Medicine, Jimma University, Jimma, Ethiopia. P.O. Box 378. Email: abdulhalikw@gmail.com.

\section{Competing interests}

The authors declare that they have no competing interests.

\section{Consent to publication}

Consent to publish this article was not applicable since it did not contain any individual person's data.

\section{Ethical approval and consent to participate}

Ethical approval and clearance was obtained from institutional review board of Jimma University, College of Health Sciences and Medicine. Letter of cooperation was obtained from Wolaita zonal health department to the respective health facilities. Verbal informed consent was obtained from study participants by assuring confidentiality and by informing the purpose of the study.

\section{Author details}

${ }^{1}$ School of Public Health, College of Health Sciences and Medicine, Wolaita Sodo University, Wolaita SodoP.O.Box 138Ethiopia. ${ }^{2}$ Department of Epidemiology, College of Health Sciences and Medicine, Jimma University, JimmaP.O.Box 378Ethiopia.

Received: 16 October 2015 Accepted: 15 June 2016

Published online: 12 August 2016

\section{References}

1. Global 2015. AIDS report in the Context of Other Global Challenges [Internet]. Berlin; 2011. Available from: http://www.global2015.net/file/ global2015hiv.pdf. [Accessed 10 June 2011].

2. UNAIDS. AIDS epidemic [Internet]. 2009 [Updated 2009 Dec]. Available from: http://data.unaids.org/pub/Report/2009/JC1700_Epi_Update_2009_en.pdf. [Accessed Nov 2009].

3. UNAIDS. The Millennium Development Goals Report [Internet]. United Nations Department of Economic and Social Affair. New York; 2010. Available from: http://mdgs.un.org/unsd/mdg/Resources/Static/Products/ Progress2010/MDG_Report_2010_En.pdf. [Accessed June 2010].

4. Global report; UNAIDS report on the global AIDS epidemic 2010. Joint United Nations Programme on HIV/AIDS (UNAIDS). Available from: http:// www.unaids.org/globalreport/documents/20101123_GlobalReport_full_en. pdf. [Accessed Jul 2010].

5. FHAPCO. Contry progress report on the HIV response. UNAIDS. Addis Ababa; 2014. Available from: http://www.unaids.org/sites/default/files/ country/documents/ETH_narrative_report_2014.pdf. [Accessed Mar 2014].

6. FHAPCO. Annual Performance Report of Multisectoral HIV/AIDS Response [Internet]. Addis Ababa; 2009/2010. Available from: http://data.unaids.org/ pub/Report/2009/JC1700_Epi_Update_2009_en.pdf.

7. $\mathrm{MOH}$. Report on progress towards implementation of the UN Declaration of Commitment on HIV/AIDS. Federal HIV/AIDS Prevention and Control Office. Addis Ababa; March 2010. Available at: http://data.unaids.org/pub/Report/ 2010/ethiopia_2010_country_progress_report_en.pdf.

8. FHAPCO. AIDS in Ethiopia, 6th report, HIV/AIDS Prevention \& Control Office [Internet]. Available from: http://www.etharc.org/aidsineth/publications/ aidsineth6th en.pdf. [Accessed Dec 2011].

9. WHO. Guidance on Provider-Initiated Testing and Counseling in Health Facilities [Internet]. Addis Ababa: World Health Organization; UNAIDS; May 2007. Available from: http://www.who.int/hiv/pub/guidelines/ 9789241595568 en.pdf.

10. FMoH. Guidelines for HIV Counseling and Testing in Ethiopia [Internet]. Addis Ababa; July 2007. Available from: http://www.who.int/hiv/topics/vct/ ETH_HCT_guidelinesJune26_clean.pdf. [Accessed Oct 2008].

11. WHO. Towards Universal Access: Scaling up priority HIV/AIDS interventions in the health sector. Geneva, Switzerland; 2008. Available at: http://www. who.int/hiv/pub/2010progressreport/en/.

12. $\mathrm{FMoH}$. National training package on Provider-initiated pediatric HIV testing and counseling, participant's manual. Addis Zambia; 2010. Available from: http://icap.columbia.edu/resources/detail/pediatric-hiv-care-and-treatmentnational-guidelines-and-manual-zambia. [Accessed Feb 2004].

13. WHO. Provider-initiated HIV testing and counseling: one-day training manual. April 2011. Available from: http://whqlibdoc.who.int/publications/ 2011/9789241501293_eng.pdf. [Accessed 10 Aug 2016].

14. WHO. HIV/AIDS in the Context of Other Global Challenges Special Report for the UN High-Level Meeting on AIDS. 2011.

15. FHAPCO. Annual Performance Report of Multisectoral HIV/AIDS Response [Internet]. Addis Ababa; 2010. Available from: http://www.lo.org/wcmsp5/ groups/public/_ed_protect/_protrav/_ilo_aids/documents/ legaldocument/wcm.

16. Nakanjako D, Kamya M, et al. Acceptance of Routine Testing for HIV among Adult Patients at the Medical Emergency Unit at a National Referral Hospital in Kampala. Uganda; AIDS Behav. doi:10.1007/s10461-006-9180-9. Available at: http://chs.mak.ac.ug/system/files/Nakanjako-chs-res.pdf. 
17. Topp ST, Chipukuma JM, Chiko MM, et al. Opt-out provider-initiated HIV testing and counseling in primary care outpatient clinics in Zambia. Bulletin of the World Health Organization. 2011;89:328-335A. doi:10.2471/BLT.10. 084442. Available at: http://www.who.int/bulletin/volumes/89/5/10-084442/.

18. Girma S, Enquselassie F. Uptake of provider-initiated HIV counseling and testing (PICT) among out- patient department (OPD) clients with possible clinical signs of HIV infection in Addis Ababa. Ethiop Med J. 2009;47(4):245-54.

19. CSA. Population and Housing Census Report-Country - 2007, Central Statistical Agency, 2010-07, English [eng], Ethiopia [eth]. Addis Ababa; 2007. Available at: http://www.csa.gov.et/index.php/2013-02-20-14-51-51/2013-0401-11-53-00/census-2007.

20. SNNPR. Investment expantion in Southern Ethiopia. 2011. Available at: http://www.southinvest.gov.et/potentialWolayta.htm.

21. Ayenew A, Leykun A, Colebunders R, Deribew A. Predictors of HIV Testing among Patients with Tuberculosis in North West Ethiopia: A Case-control Study. PLoS ONE 5(3): e9702. doi:10.1371/journal.pone.0009702.

22. USAID. HIV/AIDS Health Profile: Sub-Saharan Africa. July 5, 2012. Available from: http://pdf.usaid.gov/pdf_docs/pdacu659.pdf.

23. Assefa $A$, Degnet $A$, Andinet $D$, et al. Impact evaluation of the Ethiopian Health Services Extension Programme. Journal of Development Effectiveness. 2009;1 (4). Available from: http://www.tandfonline.com/doi/ abs/10.1080/19439340903375724.

24. Netsanet W, Amsalu F. Missed opportunities for earlier HIV testing and diagnosis at the health facilities of Dessie town, North East Ethiopia. BMC Public Health. 2010;10:362.

25. Getachew W. Factors associated with VCT utilization in Guraghe Zone, South Ethiopia [Masters Thesis]. Addis Ababa University; April 2004.

26. Sheri $D$, Michele $H$, Karen $L$, et al. Routine HIV testing in Botswana: a population-based study on attitudes, practices, and human rights concerns. PLoS Medicine. 2005

27. Addisu B, Abebe G. Factors affecting acceptance of HIV testing among antenatal care attendee: with emphasis on role of male partners. International Journal of Scientific \& Engineering Research. Volume 3, Issue 4, April-201. Available from: http://www.ijser.org/.

28. Maru M, Ali A. Assessment of VCT utilization and willingness to accept provider-Initiated HIV counseling and testing among tuberculosis patients in Addis Ababa. Addis Ababa University; 19-Apr-2008. Available from: http://etd.aau.edu.et/handle/123456789/3031.

29. Hussein M, Tahir H. Acceptability of provider-initiated HIV counseling and testing in pregnant mothers attending ANC at Nekemte town government health facilities East Wollega zone, Nekemte. Addis Ababa University; 10May-2012. Available from: http://hdl.handle.net/123456789/2957.

30. Degu J, Aschalew E, Bernt L. Acceptability of HIV counseling and testing among tuberculosis patients in south Ethiopia. BMC Int Health Hum Rights. 2007;7:4.7.

31. Demisse A, Deribew A, Abera M. Determinants of acceptance of voluntary HIV testing among antenatal clinic attendees at Dil Chora Hospital, Dire Dawa, East Ethiopia. Ethiop J Health Dev. 2009:23(2):141-7.

32. Legese A, Ahmed A. Factors affecting willingness to HIV Counseling and Testing among patients presenting with conventional Sexually Transmitted Infections in Addis Ababa. Ethiop J Health Dev. 2011;25(2):116-125. Available from: http://ejhd.uib.no/ejhd-v25-no2/116\%20Factors\%20 affecting\%20willingness\%20to\%20HIV\%20Counseling\%20and. [Accessed 10 Aug 2016].

33. Fatuma S, Getnet M. Assessment of acceptability of provider-initiated HIV counseling and testing among Tuberculosis patients on DOTS in Adama city administration [Masters Thesis]. Addis Ababa University; July 2008.

34. Steen TW, Seipone K, Gomez Fde L, et al. Two and a half years of routine HIV testing in Botswana. J Acquire Immune Defic Syndr. 2007;44(4):484-8. Available at: http://www.ncbi.nlm.nih.gov/pubmed/17211281.

\section{Submit your next manuscript to BioMed Central and we will help you at every step:}

- We accept pre-submission inquiries

- Our selector tool helps you to find the most relevant journal

- We provide round the clock customer support

- Convenient online submission

- Thorough peer review

- Inclusion in PubMed and all major indexing services

- Maximum visibility for your research

Submit your manuscript at www.biomedcentral.com/submit 